UDC 903'1(575.2):623.444.1

Submitted: 27.06 .2020

LBC 63.442.7(5Кир)-411

Accepted: 24.11.2020

\title{
TWO NEW DAGGERS OF EARLY SARMATIAN SHAPE FROM CHUI VALLEY
}

\author{
Sergei S. Ivanov \\ Kyrgyz National University named after J. Balasagyn, Bishkek, Kyrgyzstan
}

\begin{abstract}
The article is concerned with the publication of two new finds of early Sarmatian shape iron daggers, found in the southern foothill zone of the Chui valley (Kyrgyzstan). This category of weapons is considered as a rare find on the territory of the spread of the Saka culture of Tien Shan region. Therefore, each new find of such items significantly expands the understanding of the features of the formations and development of the blade weapons in this territory. The first dagger by its morphological features was dated to the late half of the $5^{\text {th }}$ - first half of the $4^{\text {th }}$ centuries BC. Similar analogies were discovered on the territory of the Forest-Steppe Altai, the Volga region and the South Urals, which allowed to clarify its chronological framework. The second dagger was dated by the author back to the first half of the $3^{\text {rd }}$ century BC. At the same time the closest morphological parallels are found mainly in the Sarmatian materials of the South Urals region. Analysis of the data of the two daggers showed that Tien Shan region was already quite early in the southern periphery of the original territory of formation of the early Sarmatian-type blade weapons. It is noteworthy that cultural interrelationships not only with the territories of the Southern Urals and Volga region, but also with the Forest-Steppe Altai, played a significant role in appearance and spread of the daggers there.
\end{abstract}

Key words: Early Iron Age, ancient nomads, Tien Shan region, weapons, iron daggers.

Citation. Ivanov S.S., 2020. Dva novyh kinzhala rannesarmatskogo oblika iz Chuyskoy doliny [Two New Daggers of Early Sarmatian Shape from Chui Valley]. Nizhnevolzhskiy Arkheologicheskiy Vestnik [The Lower Volga Archaeological Bulletin], vol. 19, no. 2, pp. 120-128. DOI: https://doi.org/10.15688/nav.jvolsu.2020.2.6

УДК 903'1(575.2):623.444.1

ББК 63.442.7(5Кир)-411
Дата поступления статьи: 27.06.2020

Дата принятия статьи: 24.11.2020

\section{ДВА НОВЫХ КИНЖАЛА РАННЕСАРМАТСКОГО ОБЛИКА ИЗ ЧУЙСКОЙ ДОЛИНЫ}

\author{
Сергей Сергеевич Иванов \\ Кыргызский национальный университет им. Ж. Баласагына, г. Бишкек, Киргизия
}

\begin{abstract}
Аннотация. Статья посвящена публикации двух новых находок железных кинжалов раннесарматского облика, найденных в южной предгорной зоне Чуйской долины (Киргизия). Данная категория вооружения считается достаточно редкой на территории распространения сакской культуры Притяньшанья. Поэтому каждая новая находка подобных предметов существенно расширяет представления об особенностях формирования и развития клинкового оружия на этой территории. Первый кинжал по своим морфологическим особенностям был датирован второй половиной $\mathrm{V}$ - первой половиной IV в. до н.э. Он находит близкие аналогии на территории Лесостепного Алтая, Поволжья и Приуралья, которые позволили уточнить его хронологические позиции. Второй кинжал был отнесен автором к первой половины III в. до н.э. При этом ближайшие морфологические параллели он находит преимущественно в сарматских материалах Южного Урала. Анализ данных двух кинжалов показал, что Притяньшанье уже достаточно рано входило в южную периферию первоначальной территории сложения клинкового оружия раннесарматского типа. Примеча; тельно, что в его появлении и распространении здесь значительную роль сыграли культурные взаимосвязи не только с территориями Южного Приуралья и Поволжья, но и также с Лесостепным Алтаем.

Ключевые слова: ранний железный век, ранние кочевники, Притянышанье, вооружение, железные кинжалы.

Цитирование. Иванов С. С., 2020. Два новых кинжала раннесарматского облика из Чуйской долины // Нижневолжский археологический вестник. Т. 19, № 2. С. 120-128. DOI: https://doi.org/10.15688/nav.jvolsu.2020.2.6
\end{abstract}


Комплекс вооружения сакской культуры Притяньшанья все еще остается недостаточно изученной научной областью. По этой причине каждая новая находка предметов вооружения в заметной мере расширяет и детализирует наши представления об этой категории материальной культуры.

Настоящая статья посвящена двум новым находкам железных кинжалов случайного характера, сделанных в Чуйской долине. Поскольку здесь они отмечены впервые, подобный факт приобретает особое значение, так как позволяет включить этот район в зону распространения клинкового оружия раннесарматского облика в пределах Притяньшанья.

Первый кинжал был обнаружен в ущелье Чункурчак, расположенном в южной предгорной зоне Чуйской долины. Он хорошей сохранности и не имеет утрат и повреждений.

Кинжал обладает небольшим слабоизогнутым навершием и прямой гладкой рукоятью, подпрямоугольной в разрезе. Перекрестье изделия узкое, дуговидной формы, с загнутыми кверху концами. Клинок широкий, вытянуто-треугольной формы, ромбический в сечении (рис. 1,1, 2,1).

Общая длина кинжала -29 см, из которых 19 см приходится на клинок, ширина перекрестья $-7,5 \mathrm{~cm}$, ширина рукояти $-2,6 \mathrm{~cm}$, максимальная ширина клинка - 5,4 cм.

Типологически сходные образцы клинкового оружия были и раньше известны на территории сакской культуры Притяньшанья. Так, рассматриваемому кинжалу достаточно близок экземпляр из кургана 12 могильника ДжалАрык II на Западном Тянь-Шане (КетменьТюбинская долина), который датируется IV в. до н.э. [Кожомбердиев, 1977 , с. 13, рис. 3,2; Ташбаева, 2011, с. 68, рис. 59,2; Иванов, 2018б, c. 215 , рис. 1,2$]$. Также близкими морфологическими особенностями обладает рукоять длинного меча из кургана Иссык, надежно датирующегося IV в. до н.э. [Акишев, 1978, c. 30 , табл. 43].

Аналогии кинжалу из Чункурчака известны также в других районах Средней Азии. В частности, относительно сходный экземпляр зафиксирован в кургане 9 могильника Памирская I на Восточном Памире, который также отнесен к IV в. до н.э. [Бернштам, 1956, рис. 4; Литвинский, 1972, с. 117, табл. 40,6].
Близкий кинжал, но не с прямой, а эллипсоидной рукоятью, происходит из окрестностей с. Берел в Восточном Казахстане, который был датирован в пределах IV-III вв. до н.э. [Caмашев и др., 2004, с. 233, рис. 9,1].

В значительном количестве аналогичные кинжалы и мечи известны из раннесарматских погребальных памятников Поволжья и Южного Приуралья, где они относятся к IV в. до н.э. [Смирнов, 1961, с. 26-27, рис. 7,9-11; Мошкова, 1963, с. 33, табл. 18,10; Клепиков, 2002 , с. $27-28$, рис. 2,6-10]. Сходный экземпляр короткоклинкового оружия также происходит с территории Горного Алтая и датирован IV в. до н.э. [Кочеев, 1995, с. 133-135, рис. 1,2].

Стоит еще остановиться на такой особенности первого чуйского кинжала, как наличие загнутых кверху концов перекрестья, которая, как оказалось, позволяет уточнить его хронологию. Так, целый ряд кинжалов с аналогичной морфологической особенностью известны в погребальных комплексах каменской культуры Лесостепного Алтая. Но практически все они имеют узкое перекрестье в виде сломанного под углом бруска. П.И. Шульга склонен отнести данные кинжалы к V-IV вв. до н.э. [Шульга, 2007, с. 147, рис. 2,8,10]. К сходному мнению о более ранней хронологической позиции кинжалов с загнутыми кверху концами перекрестья приходят публикаторы очень близкого кинжала из пос. Новоберезовский (Аглос) в Самарском Поволжье, который отличается от чуйского лишь наличием прорезной рукояти [Мышкин и др., 2007, с. 41, рис. 3,2]. Но они склонны датировать данный экземпляр второй половиной V - первой половиной IV в. до н.э.

Вероятнее всего, первый кинжал из Чуйской долины датируется в этих же хронологических рамках. Отсутствие ему параллелей в оформлении перекрестья на территории Притяньшанья заставляет думать, что он мог здесь появиться в результате влияния каменской культуры Лесостепного Алтая, тесные культурные и этнические контакты с которой местная сакская культура демонстрирует на протяжении второй половины VI первой половины ІІ вв. до н.э. (подробнее см.: [Иванов, 2016, с. 869-885]). Это тем более возможно, если учесть, что, по-видимому, именно этот регион был изначальным мес- 
том формирования железных кинжалов с ранними формами перекрестий с загнутыми концами. На это указывает то, что отмеченный выше кинжал из Самарского Поволжья обладает таким характерным «восточным» признаком, как прорезная рукоять - основная часть кинжалов, обладающая ею, концентрируется в Восточном Казахстане и на Алтае [Мышкин и др., 2007, с. 41].

Все это дает нам основание предполагать, что и чуйский кинжал мог появиться здесь в результате сложных процессов формирования и распространения ранних железных кинжалов раннесарматского типа на территории от Алтая до Южного Урала, отмечая при этом южную периферию данных процессов.

Второй кинжал был найден в юго-восточной предгорной части Чуйской долины (район пос. Бордунский). Он имеет хорошую сохранность, но у него утрачено навершие.

Кинжал имеет узкое изогнутое перекрестье. Рукоять у него обладает эллипсоидной формой, то есть сужается к перекрестью и навершию, в сечении она округлая. На ее верхнюю часть надета небольшая обойма, над которой расположен прямоугольный в разрезе черенок, на котором было закреплено не сохранившееся навершие. Клинок прямой, в средней части незначительно расширяется, но затем сужается к острию. На клинковой части хорошо просматриваются два продольных неглубоких дола, образующие центральное ребро жесткости на нем (рис. 1,2, рис. 2,2).

Общая длина сохранившейся части кинжала - 27 см, из которых 18,5 см приходится на клинок, ширина перекрестья - 5,2 см, диаметр рукояти - 1,6 см, максимальная ширина клинка $-3,2 \mathrm{cм}$.

Как отмечалось выше, кинжалы с дуговидным перекрестьем получают наибольшее распространение в IV - начале III в. до н.э.

Дополнительным аргументом в пользу отнесения второго чуйского кинжала к этому времени выступает наличие у него эллипсоидной рукояти, характерной для целого ряда кинжалов и мечей раннесарматского облика как в Притяньшанье, так и за его пределами.

На территории рассматриваемого региона образцы клинкового оружия с подобными рукоятями отмечены на нескольких кинжалах из погребальных памятников на Западном
Тянь-Шане (Кетмень-Тюбинская долина), где они датируются IV-III вв. до н.э. [Ташбаева, 2011 , с. $68-69,86-87$, рис. $59,1,2,60,1-3$; Иванов, 2018a, с. 167-168, рис. 1,1-3]. Они известны у кинжала и меча из кургана Иссык IV в. до н.э. в Семиречье [Акишев, 1978, с. 28-30, табл. 23-24].

Кинжал с аналогичной рукоятью был найден в соседнем Приферганье, в Исфаринской долине, и отнесен к IV-III вв. до н.э. [Негматов, 1987, с. 53-54, рис. 3]. Рукоять этого типа имеется у одного кинжала из Храма Окса (Тахти-Сангин) в Северной Бактрии, отнесенного Б.А. Литвинским к концу IV - III в. до н.э., который отмечает при этом, что более склоняется к концу предложенной им датировки [Литвинский, 2001, с. 207, 244-245, 248, табл. 58,5].

Серия кинжалов с эллипсоидными рукоятями отмечены также на территории каменской культуры в Лесостепном Алтае, где они датируются IV - началом III в. до н.э., с возможным заходом также в V в. до н.э. [Могильников, 1997 , с. $43-46$, рис. $37,3,5,6,8,39,5$; Шульга, 2007, с. 147, рис. 2,10]. Отдельные их экземпляры известны из соседних Восточного Казахстана [Самашев и др., 2004, с. 233, рис. 9,1], Горного Алтая [Кочеев, 1995, с. 83, рис. 1,2], Минусинской котловины [Красниенко, Субботин, 2013, табл. $1, X-10]$ и Тувы [Cеменов, 2003, с. 28, табл. 32,23].

Единичные мечи и кинжалы с подобными рукоятями происходят с территории распространения раннесарматской культуры в Южном Приуралье [Смирнов, 1961, с. 26-27, рис. 7,11; Мошкова, 1963, с. 34, табл. 18,9,11], а также в соседнем Зауралье [Смирнов, 1961, с. 25 , рис. 5,5; Мошкова, 1974, с. 25-26, рис. 5,9$]$, где они датируются в пределах IVIII вв. до н.э.

Итак, хронология эллипсоидных рукоятей на кинжалах и мечах раннесарматского, в том числе и на территории распространения сакской культуры Притяньшанья, облика достаточно твердо укладывается в IV-III вв. до н.э., что позволяет датировать второй кинжал из Чуйской долины в этих же хронологических рамках.

Также обращает на себя внимание наличие долов на клинке у второго чуйского кинжала, достаточно редких для кинжалов и ме- 
чей скифо-сакского периода. Они впервые отмечены на клинковом оружии в Притяньшанье. На территории ближайших регионов аналогичный прием оформления клинковой части имеется на целой серии кинжалов и мечей раннесарматского периода в Южном Приуралье, причем преимущественно характерен для его завершающего этапа [Исмагил, 2001, c. 119-120, табл. III, 22, IV,31,34-38, V,39-48, VI,50-53,57-58, X,95,97-98,100,107,109, XIII, 141,144; Мошкова, 1963, с. 34].

Показательно также то, что заметная часть кинжалов с долами из Южного Приуралья имеет сходную форму клинка, что также указывает на их определенную хронологическую близость с чуйским.

За пределами Южного Приуралья удалось найти только одну аналогию с долами на лезвийной части - это длинный железный меч из с. Ключи в Лесостепном Алтае. Данный меч имеет характерные черты раннесарматского клинкового оружия - дуговидное навершие и прямое перекрестье, но в то же время он обладает одной архаичной деталью - прорезной рукоятью, типичной для кинжалов преимущественно в VI-III вв. до н.э. [Мышкин и др., 2007, с. 41; Денисов, 2010, с. 202-204]. С учетом сочетания всех этих морфологических признаков меч был не без оснований отнесен к IV-III вв. до н.э. [Могильников, 1997, с. 45 , рис. 39,2$]$.

С учетом наличия у второго чуйского кинжала такой детали, как долы на лезвийной части, характерные преимущественно для клинкового оружия в основном в III-II вв. до н.э., его датировку можно сузить, по крайней мере до начала - первой половины III в. до н.э.

Новые находки железных кинжалов раннесарматского облика в Чуйской долине впервые отмечены, что не только закрывает своего рода «белое пятно», но и позволяет включить этот район в рамках Притяньшанья в зону их распространения. С другой стороны, находка кинжала из Чункурчака дает основания расширить традиционную дату их проявления в регионе и отнести ко второй половине $\mathrm{V}$ в. до н.э., то есть уже к начальному периоду их оформления на соседних территориях. Что, в свою очередь, дает основания включить Притяньшанье в южную периферию ареала сложения клинкового оружия раннесарматского облика. 


\section{ИЛЛЮСТРАЦИИ}

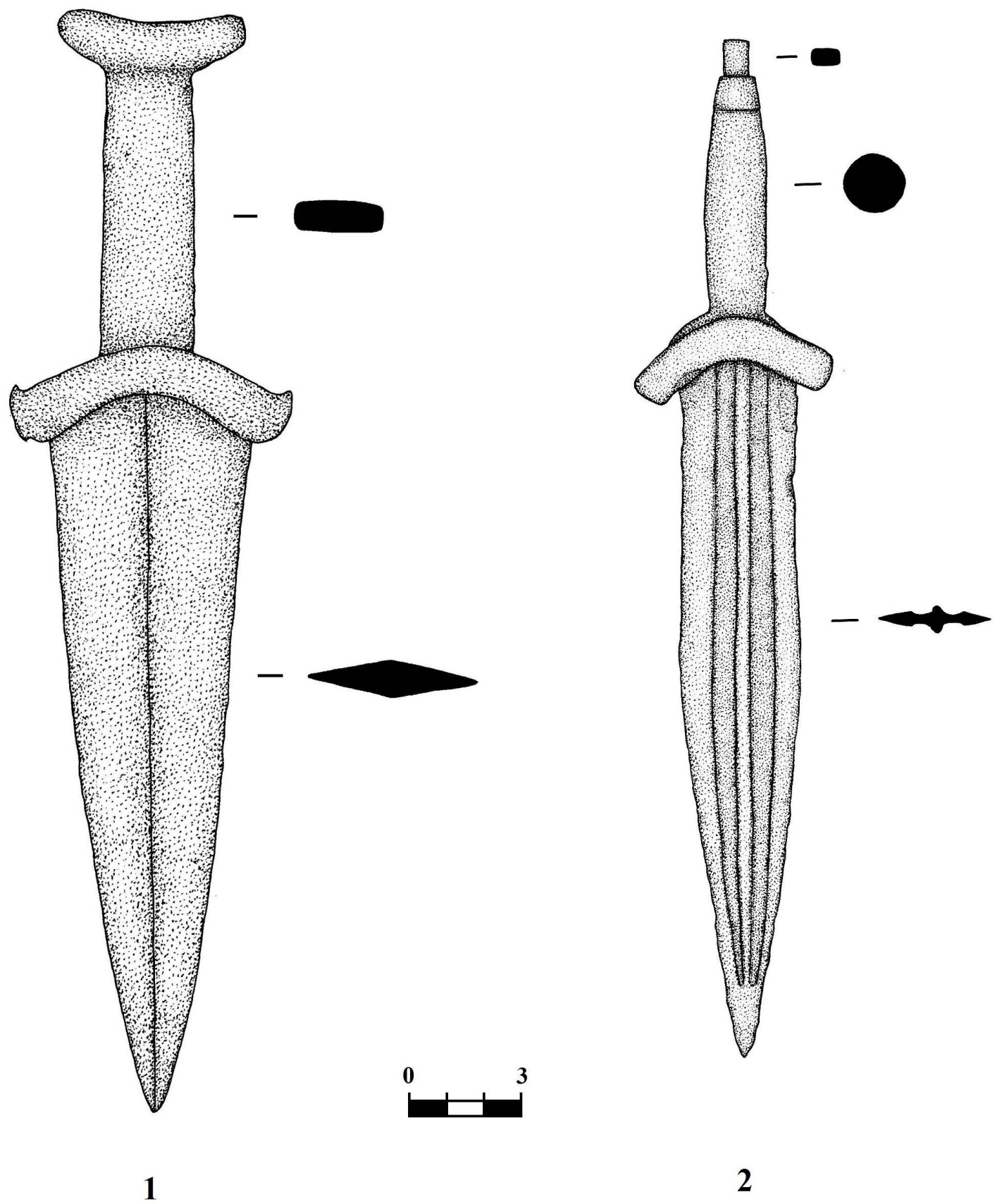

Рис. 1. Кинжалы раннесарматского облика из Чуйской долины (прорисовки автора):

1 - ущелье Чункурчак; 2 - район пос. Бордунский

Fig. 1. Daggers of early Sarmatian type from Chu valley (authors drawings):

1 - Chunkurchak gorge; 2 - area of Bordunskiy settlement 


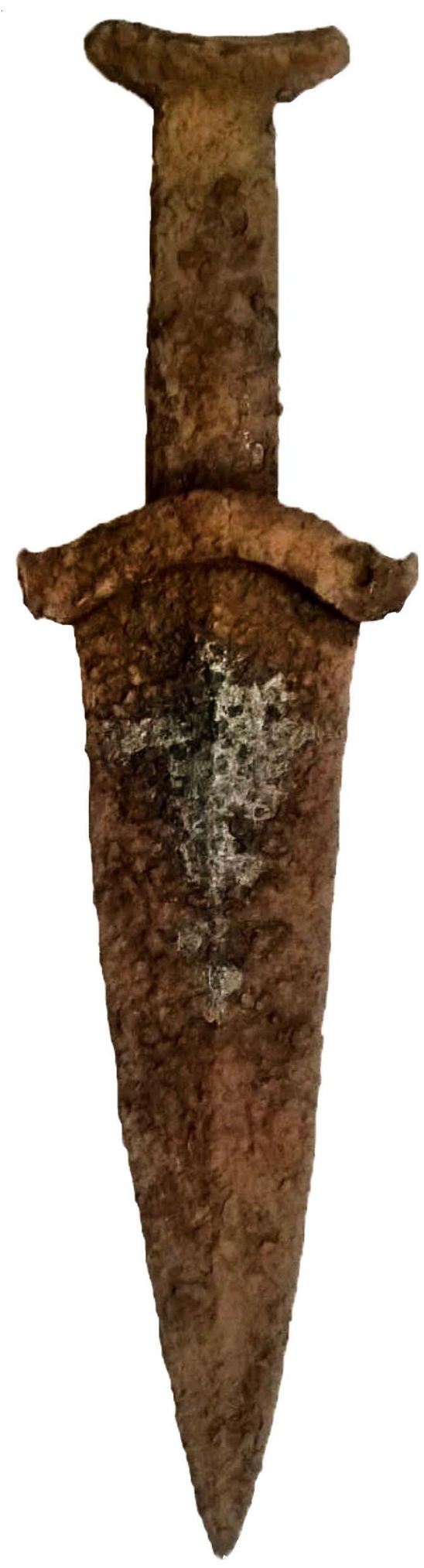

1

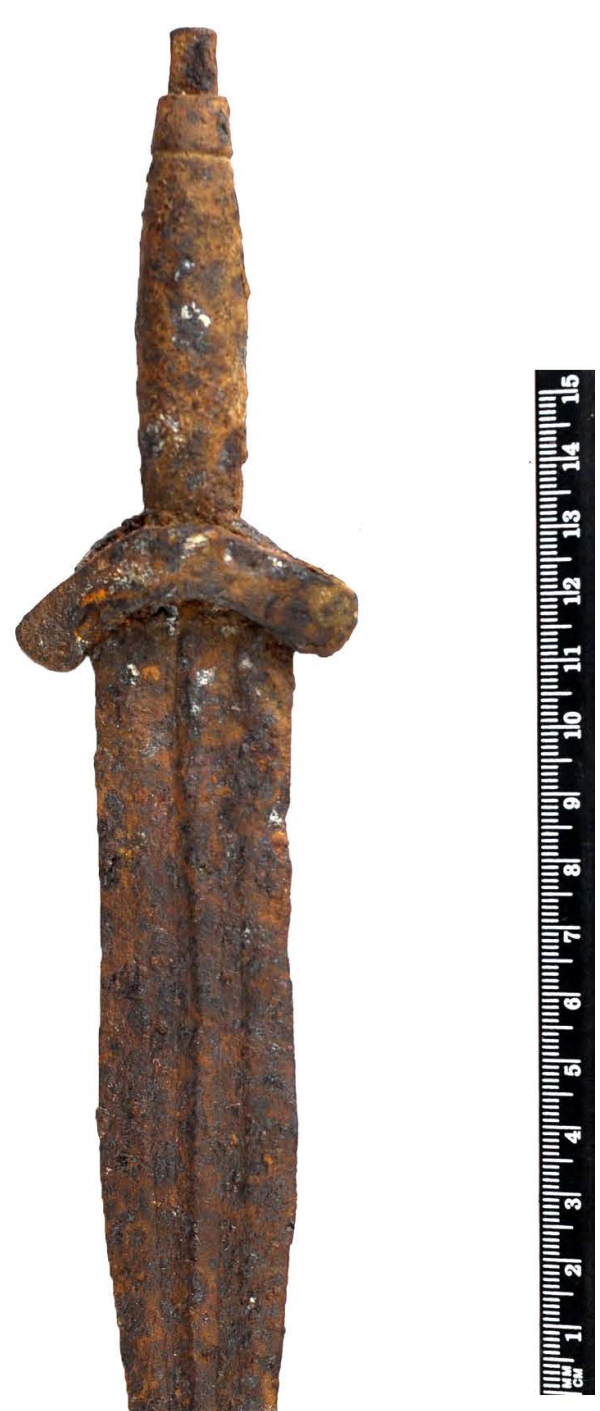

2

Рис. 2. Кинжалы раннесарматского облика из Чуйской долины (автор фото П.И. Мокин)

Fig. 2. Daggers of early Sarmatian type from Chu valley (photo by P.I. Mokin) 


\section{СПИСОК ЛИТЕРАТУРЫ}

Акишев К. А., 1978. Курган Иссык. Искусство саков Казахстана. М. : Искусство. 132 с.

Бернштам А. Н., 1956. Саки Памира // Вестник древней истории. № 1. С. 121-134.

Денисов А. В., 2010. Мечи и кинжалы с прорезными рукоятями с территории Самарского Поволжья и Южного Приуралья // XVIII Уральское археологическое совещание: культурные области, археологические культуры, хронология. Уфа : БГПУ им. М. Акмуллы. С. 202-204.

Иванов С. С., 2016. Этнокультурные взаимосвязи ранних кочевников Притяньшанья и Алтая в скифо-сакскую эпоху // Мир Большого Алтая. № 2 (4.2). С. 869-885.

Иванов С. С., 2018а. Мечи и кинжалы с раннесарматского облика с эллипсоидными рукоятями в Средней Азии // Мир Большого Алтая. № 4 (1). С. 166-176.

Иванов С. С., 2018б. Кинжалы раннесарматского облика с территории сакской культуры Притяньшанья // ХХІ Уральское археологическое совещание. Самара : Изд-во СГСПУ. С. 214-217.

Исмагил Р. Б., 2001. Клинковое оружие эпохи ранних кочевников из Южного Приуралья (случайные находки) // У фимский археологический вестник. Вып. 3. С. 117-147.

Клепиков В. М., 2002. Сарматы Нижнего Поволжья в IV-III вв. до н.э. Волгоград : Изд-во ВолГУ. 216 с.

Кожомбердиев И. К., 1977. Основные этапы истории культуры Кетмень-Тюбе // Кетмень-Тюбе. Археология и история. Фрунзе : Илим. С. 9-24.

Кочеев В. А., 1995. Два кинжала из Горного Алтая // Известия лаборатории археологии. Горно-Алтайск : Изд-во ГАГУ. № 1. С. $83-84$.

Красниенко С. В., Субботин А. В., 2013. У Солгонского кряжа. Археологические памятники Ужурского района (Красноярский край): история изучения и современное состояние. СПб. : ИИМК РАН. 200 с.

Литвинский Б. А., 1972. Древние кочевники «крыши мира». М. : Наука. 272 с.

Литвинский Б. А., 2001. Храм Окса в Бактрии. Т. 2. Бактрийское вооружение в древневосточном и греческом контексте. М. : Восточная литература. 530 с.

Могильников В. А., 1997. Население Верхнего Приобья в середине - второй половине I тыс. до н.э. М. : ИА PAH. $195 \mathrm{c}$.

Мошкова М. Г., 1963. Памятники прохоровской культуры. САИ. Вып. Д1-10. М. : Изд-во АН СССР. 55 с.

Мошкова М. Г., 1974. Происхождение раннесарматской (прохоровской) культуры. М. : Наука. 52 с.

Мышкин В. Н., Денисов А. В., Сташенков Д. А., 2007. Находки клинкового оружия савроматского времени в Самарском Поволжье // Самарский край в истории России. Вып. 3. Самара : СОИКМ им. П.В. Алабина. С. 39-45.

Негматов Н. Н., 1987. Бронзовые скульптуры из Исфаринской долины и их историко-культурное значение // Скифо-сибирский мир. Искусство и идеология. Новосибирск : Наука. С. 49-55.

Самашев 3. С., Базарбаева Г. А., Жумабекова Г. С., Кущ Г. А., Суворова Г. И., 2004. Археологические изыскания в казахском Алтае // Известия НАН РК. Серия общественных наук. № 1. С. 223-235.

Семенов Вл. А., 2003. Суглуг-Хем и Хайыракан - могильники скифского времени в Центрально-тувинской котловине. СПб. : Петербургское востоковедение. 240 с.

Смирнов К. Ф., 1961. Вооружение савроматов. МИА. № 101. М. : Изд-во АН СССР. 168 с.

Ташбаева К. И., 2011. Культура ранних кочевников Тянь-Шаня и Алая. Бишкек : Илим. 274 с.

Шульга П. И., 2007. Вооружение на Алтае в VI-ІІІ вв. до н.э. // Вооружение сарматов: региональная типология и хронология. Челябинск : Изд-во ЮУрГУ. С. 142-156.

\section{REFERENCES}

Akishev K.A., 1978. Kurgan Issyk. Iskusstvo sakov Kazahstana [Issyk Kurgan. The Art of Sakas of Kazakhstan]. Moscow, Iskusstvo Publ. 132 p.

Bernshtam A.N., 1956. Saki Pamira [The Sakas of Pamirs]. Vestnik drevney istorii [Journal of Ancient History], no. 1 , pp. 121-134.

Denisov A.V., 2010. Mechi i kinzhaly s proreznymi rukoyatyami s territorii Samarskogo Povolzh'ya i Yuzhnogo Priural'ya [The Swords and Daggers with Slotted Handles from the Territory of Samara Volga Region and 
South Urals]. XVIII Ural'skoe arheologicheskoe soveshchanie: kul turnye oblasti, arheologicheskie kul tury, hronologiya [XVIII Ural Archaeological Meeting: Cultural Areas, Archaeological Cultures, Chronology]. Ufa, BSPU, pp. 202-204.

Ivanov S.S., 2016. Etnokul'turnye vzaimosvyazi rannih kochevnikov Prityan'shan'ya i Altaya v skifo-sakskuyu epohu [Ethno-Cultural Relationship of Early Nomads of the Tianshan Region and Altai in Scythian-Saka Era]. Mir Bol'shogo Altaya [World of Great Altai], no. 2 (4.2), pp. 869-885.

Ivanov S.S., 2018a. Mechi i kinzhaly s rannesarmatskogo oblika s ellipsoidnymi rukoyatyami v Sredney Azii [Daggers and Swords of Early Sarmatian Shape with Ellipsoidal Handles in Central Asia]. Mir Bol shogo Altaya [World of Great Altai], no. 4 (1), pp. 166-176.

Ivanov S.S., 2018b. Kinzhaly rannesarmatskogo oblika s territorii sakskoy kul'tury Prityan'shan'ya [Daggers of Early Sarmatian Type from the Territory of Saka Culture of Tien Shan Region]. XXI Ural 'skoe arheologicheskoe soveshchanie [XXI Ural Archaeological Meeting]. Samara, SSSPU, pp. 214-217.

Ismagil R.B., 2001. Klinkovoe oruzhie epohi rannih kochevnikov iz Yuzhnogo Priural'ya (sluchaynye nahodki) [Bladed Weapons of Ancient Nomads Epoch from South Urals]. Ufimskiy arheologicheskiy vestnik [The Ufa Archaeological Herald], iss. 3, pp. 117-147.

Klepikov V.M., 2002. Sarmaty Nizhnego Povolzh'ya v IV-III vv. do n.e. [The Sarmatians of Lower Volga Region in IV-III Centuries BC]. Volgograd, VolSU, $216 \mathrm{p}$.

Kozhomberdiev I.K., 1977. Osnovnye etapy istorii kul'tury Ketmen'-Tyube [The Main Stages of Cultural History of Ketmen'-Tyube]. Ketmen'-Tyube. Arheologiya i istoriya [Ketmen'-Tyube. The Archaeology and History]. Frunze, Ilim Publ., pp. 9-24.

Kocheev V.A., 1995. Dva kinzhala iz Gornogo Altaya [Two Daggers from Altai Mountains]. Izvestiya laboratorii arheologii [Proceedings of Laboratory of Archaeology]. Gorno-Altaysk, GAGU Publ., no. 1, pp. 83-84.

Krasnienko S.V., Subbotin A.V., 2013. U Solgonskogo kryazha. Arheologicheskie pamyatniki Uzhurskogo rayona (Krasnoyarskiy kray): istoriya izucheniya i sovremennoe sostoyanie [Near Solgon Ridge. The Archaeological Monuments Uzhur Area (Krasnoyarsk Region)]. Saint Petersburg, IHMC RAS. 200 p.

Litvinskiy B.A., 1972. Drevnie kochevniki «kryshi mira» [The Ancient Nomads of "Roof of the World"]. Moscow, Nauka Publ. 272 p.

Litvinskiy B.A., 2001. Khram Oksa v Baktrii. T. 2. Baktriyskoe vooruzhenie v drevnevostochnom i grecheskom kontekste [The Temple of Oxus in Bactria. Vol. 2. Bactrian Armament in the Ancient Eastern and Greek Context]. Moscow, Vostochnaya literature Publ. 530 p.

Mogil'nikov V.A., 1997. Naselenie Verhnego Priob'ya v seredine - vtoroy polovine I tys. do n.e. [The Population of the Upper Ob' Region in the Middle-Second Half of the It $^{\text {st }}$ Millennium BC]. Moscow, IA RAS. 195 p.

Moshkova M.G., 1963. Pamyatniki prokhorovskoy kul'tury [The Monuments of Prokhorovka Culture]. Svod Arkheologicheskih Istochnikov, iss. Д1-10. Moscow, USSR Academy of Sciences. 55 p.

Moshkova M.G., 1974. Proiskhozhdenie rannesarmatskoy (prohorovskoy) kul 'tury [The Origins of Early Sarmatian (Prokhorovka) Culture]. Moscow, Nauka Publ. 52 p.

Myshkin V.N., Denisov A.V., Stashenkov D.A., 2007. Nahodki klinkovogo oruzhiya savromatskogo vremeni v Samarskom Povolzh'e [Finds of Bladed Weapons of Sauromatian Period in Samara Volga Region]. Samarskiy kray v istorii Rossii [Samara Region in History of Russia], iss. 3. Samara, Samara Regional Museum of History and Local Lore named afrer P.V. Alabin, pp. 39-45.

Negmatov N.N., 1987. Bronzovye skul'ptury iz Isfarinskoy dolinyi ih istoriko-kul'turnoe znachenie [Bronze Sculptures from Isfara Valley and their Historical and Cultural Value]. Skifo-sibirskiy mir. Iskusstvo i ideologiya [ScythianSiberian World. The Art and Ideology]. Novosibirsk, Nauka Publ., pp. 49-55.

Samashev Z.S., Bazarbaeva G.A., Zhumabekova G.S., Kushch G.A., Suvorova G.I., 2004. Arheologicheskie izyskaniya v kazakhskom Altae [Archaeological Investigations in Kazakh Altai]. Izvestiya NAN RK. Seriya obshchestvennyh nauk [Proceedings of National Academy of Science, Social Science Series], no. 1, pp. 223-235.

Semenov Vl.A., 2003. Suglug-Khem i Khaiyrakan - mogil'niki skifskogo vremeni v Central'no-tuvinskoy kotlovine [Suglug-Khem and Khaiyrakan - the Cemeteries of Scythain Period in Central Tuva Basin]. Saint Petersburg, Peterburgskoe vostokovedenie Publ. 240 p.

Smirnov K.F., 1961. Vooruzhenie savromatov [The Weapons of Sauromats]. Materialy i issledovaniya po arkheologii SSSR, no. 101. Moscow, USSR Academy of Sciences. 168 p. 
S.S. Ivanov. Two New Daggers of Early Sarmatian Shape from Chui Valley

Tashbaeva K.I., 2011. Kul 'tura rannih kochevnikov Tyan'-Shanya i Alaya [The Culture of Ancient Nomads of Tien Shan and Alai]. Bishkek, Ilim Publ. 274 p.

Shul'ga P.I., 2007. Vooruzhenie na Altae v VI-III vv. do n.e. [The Weapons in Altai in VI-III Centuries BC]. Vooruzhenie sarmatov: regional'naya tipologiya i khronologiya [The Weapons of Sarmatians: Regional Typology and Chronology]. Chelyabinsk, SUSU, pp. 142-156.

\section{Information About the Author}

Sergei S. Ivanov, Candidate of Science (History), Associate Professor, Kyrgyz National University named after J. Balasagyn, Frunze St, 547, 720033 Bishkek, Kyrgyzstan, sak@yandex.ru, https://orcid.org/0000-0002-4081-3749

\section{Информация об авторе}

Сергей Сергеевич Иванов, кандидат исторических наук, доцент, Кыргызский национальный университет им. Ж. Баласагына, ул. Фрунзе, 547, 720033 г. Бишкек, Киргизия, sak@yandex.ru, https://orcid.org/0000-0002-4081-3749 